\title{
Outrigger tuned inertial mass electromagnetic transducers for high-rise buildings subject to long period earthquakes
}

\author{
Takehiko Asai \\ Assistant Professor \\ Faculty of Engineering, Information and Systems \\ University of Tsukuba \\ Tsukuba, Ibaraki 305-8573, Japan \\ Yuta Watanabe \\ Graduate Student \\ Graduate School of Systems and Information Engineering \\ University of Tsukuba \\ Tsukuba, Ibaraki 305-8573, Japan
}

\begin{abstract}
This paper proposes outrigger tuned inertial mass electromagnetic transducer (TIMET) systems for high-rise buildings subject to long period earthquake excitations. The proposed outrigger TIMET systems consist of the outrigger and TIMET parts.The outrigger damping systems have been proposed as a novel energy dissipation approach to high-rise buildings, in which control devices are installed vertically between the outrigger and perimeter columns to achieve large energy dissipation. While the TIMET has been developed based on the mechanism of the tuned viscous mass damper (TVMD) which can improve energy absorbing capability by taking advantage of resonance effect. However, instead of a viscous material, the damping of the TIMET is provided by a motor which can convert mechanical energy to electrical energy. The focus of this study is to investigate the structural control performance and energy harvesting efficiency of the proposed outrigger TIMET system for high-rise buildings subjected to long period earthquakes through numerical simulations.
\end{abstract}

Keywords: Outrigger damping system, Tuned inertial mass electromagnetic transducer, Energy harvesting, High-rise building, Long period earthquake

Email addresses: asai@kz.tsukuba.ac.jp (Takehiko Asai), s1720987@s.tsukuba.ac.jp (Yuta Watanabe)

Preprint submitted to Journal of ${ }^{A} T_{E} X$ Templates

February 27, 2018 


\section{Introduction}

As new materials and technologies have been developed, the number of highrise buildings has been rapidly increasing especially in urban areas all over the world. However, at the same time this achievement brings new problems regarding protection of these buildings against strong winds and severe earthquakes. In particular, because high-rise buildings have dominant natural frequencies in low frequency range, the vulnerability to long period earthquakes has been pointed out. Therefore structural control strategies targeting the specified frequency range is demanding for protecting high-rise buildings.

Traditionally, a tuned mass damper (TMD) [1] has been employed to accomplish this objective. However, due to the restricted auxiliary mass for practical reasons, the effectiveness of the TMD systems to earthquake ground motions is limited [2]. To address this issue, recently, for the purpose of the seismic response reduction of civil structures, various types of control devices utilizing a tuned inerter has been developed by many researchers, including the tuned viscous mass damper (TVMD) [3], tuned inerter damper (TID) [4, 5], tuned mass damper inerter (TMDI) [6], and T tuned inerter damper (TTID) [7]. As explained in [8] originally, the amplified equivalent mass effect, i.e., inertance, is realized by a mechanism such as the hydraulic [9], ball screw [3], or rack and pinion inerter $[8,10]$ and the force proportional to the relative acceleration between both ends is produced.

For example, the TVMD proposed in [3] consists of two parts: a rotational mass damper and a tuning spring. Moreover, the rotational mass damper part can be divided into a ball screw mechanism, a rotating mass, and a viscous damper. The ball screw mechanism is employed to convert translational motion to rotational behavior. Then by rotating the relatively small physical mass, an amplified equivalent mass effect, i.e., inertance, is obtained. The device producing up to on the order of thousandfold equivalent mass has been already developed [11]. This makes it possible for the TVMD to realize large mass ratio to the structure enough that a typical TMD can not realize. And the input energy is absorbed by the viscous material as heat. In this system, the inertance and the viscous damper are connected in parallel and the tuning spring is arranged in series with them. Then the TVMD is connected to the structure through the spring. Thus the energy absorption efficiency and vibration mitigation performance can be improved by tuning the spring stiffness so that the rotational inertial mass resonates with the structure [3].

Based on the mechanism of the TVMD, the first author proposed a tuned inertial mass electromagnetic transducer (TIMET) [12], in which a motor is employed instead of a viscous material to convert mechanical energy into electrical energy. And the effectiveness of the TIMET on the civil structures subjected to earthquake loadings was verified using the small-scale three story benchmark building model through numerical simulation studies [13]. During seismic events, an external power source is not guaranteed, so the generated energy by the motor is of value to self-powered control, structural health monitoring, emergency power supply and so on. Similar energy harvesting devices employing 
(a)

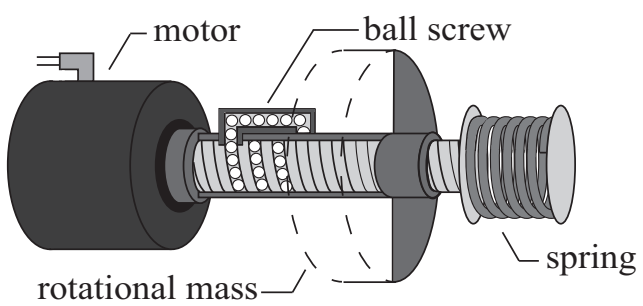

(b)

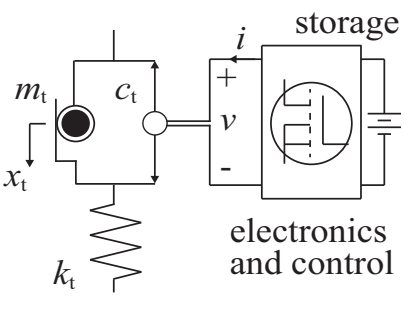

Figure 1: TIMET: (a) Schematic illustration, (b) Model

the tuned inerter mechanism for civil structures have been proposed by other researchers $[14,15]$.

In this research, to take full advantage of the TIMET on high-rise buildings, the outrigger damping system $[16,17,18]$ is combined with the TIMET. The outrigger damping system employs damping devices installed between outrigger walls and perimeter columns in a frame-core-tube structure to enhance structural dynamic performance. This paper seeks to verify the efficacy of the outrigger TIMETs for high-rise buildings subject to long period earthquakes. First the mechanism of the TIMET is reviewed briefly. Then the equation of motion of the outrigger TIMET system is developed and the parameter design method is introduced. Numerical simulation studies are carried out by using long period earthquakes and the vibration reduction performance and energy harvesting capability are investigated. Finally, conclusions obtained from this research follow.

\section{Tuned inertial mass electromagnetic transducer}

In this section, the mechanism and model of the TIMET is overviewed. Also the definition of generated energy used in this paper is derived.

\subsection{Model}

The TIMET employed in this research is illustrated schematically in Figure 1(a) and its model is shown in Figure 1(b). As can be seen, the TIMET consists of three parts: a motor, a ball screw mechanism with a rotational mass, and a turning spring. The TIMET provides damping by the motor to decay vibration and vibration energy is converted into electrical energy. In this paper, the damping coefficient provided by the motor is denoted by $c_{t}$. In parallel with the motor, inertance $m_{t}$, which is realized through a ball screw mechanism, is installed. And the linear spring whose stiffness is $k_{t}$ is installed in series with the motor and inertance. To improve energy absorbing efficiency and vibration mitigation performance, we need to design the value of $k_{t}$ and $c_{t}$ appropriately. 
The damping $c_{t}$ can be decided by controlling the current into the motor $i$. The relationship between the current and voltage is defined as

$$
i=-Y v
$$

where $Y$ is a time-invariant feedback gain, which can be adjusted by a transistor such as a MOSFET. Under this feedback law, the electrical load can be considered a resistor. Thus $Y$ has units of admittance. And the voltage $v$ can be expressed, through the back-EMF constant $e_{t}$, as

$$
v=e_{t} \dot{x}_{t}
$$

where $x_{t}$ is the displacement of the inertance $m_{t}$. Let the electromechanical transduction power be $P_{e}$ and the damping force by the motor be $f_{c}$. Since the electromechanical transduction power is preserved between mechanical and electrical sides of the transducers,

$$
P_{e}=i v=f_{c} \dot{x}_{t}
$$

with the convention that positive $P_{e}(t)$ implies energy flow from the electrical network to the mechanical system. Under this definition, the damping force by the motor is given by

$$
f_{c}=-c_{t} \dot{x}_{t}
$$

Thus from Eqs. (1), (2), and (3), we have

$$
-Y e_{t}^{2} \dot{x}_{t}^{2}=-c_{t} \dot{x}_{t}^{2}
$$

Hence the damping $c_{t}$ can be expressed as

$$
c_{t}=Y e_{t}^{2}
$$

Therefore, we know that the desired damping can be obtained by choosing appropriate $Y$. Thus, hereafter $m_{t}, k_{t}$, and $c_{t}$ are used as design parameter for the TIMET.

\subsection{Energy harvesting objective}

To assess the energy harvesting efficiency for the proposed system, the power delivered to storage needs to be defined. As in [19, 20], the power delivered to storage $P_{g}$ is defined as the power extracted by the transducer minus the transmission losses in the transducer and power electronic circuitry $P_{l}$, i.e.,

$$
P_{g}(t)=-P_{e}(t)-P_{l}(t)
$$

Typically the expression for the transmission losses $P_{l}(t)$ is quite complicated because the transmission losses happen due to various causes on the electronic hardware. However, for the purpose of this paper, we assume simply that the transmission loss is resistive; i.e.,

$$
P_{l}(t)=i^{2} R=\frac{c_{t}^{2} R}{e_{t}^{2}} \dot{x}_{t}^{2}
$$


where $R>0$ is the transmission resistance. For example, if the losses were entirely comprised of coil losses in the transducers, then $R$ is equal to the coil resistance. For more complex loss models, which incorporate MOSFET and diode conduction losses in the converters, past work has shown that these situations can also be conservatively approximated by a resistive loss term, together with a static power offset [21]. Defining $\bar{c}_{t}=e_{t}^{2} / R$, which is a positive value with units of viscous damping, gives

$$
P_{l}(t)=\frac{c_{t}^{2}}{\bar{c}_{t}} \dot{x}_{t}^{2}
$$

and physically $\bar{c}_{t}$ represents the supplemental viscous damping that would relate the velocity $\dot{x}_{t}$ to the output force $c_{t} \dot{x}_{t}$ if the coil of the transducer is shorted. Thus $\bar{c}_{t}$ is determined by the specification of the transducer and represents the maximum viscous damping the transducer can exert.

With the above definitions and assumptions, we can now define the power delivered to storage as

$$
P_{g}(t)=\left(c_{t}-\frac{c_{t}^{2}}{\bar{c}_{t}}\right) \dot{x}_{t}^{2}
$$

\section{Problem formulation}

\subsection{Uncontrolled building}

To begin with, the uncontrolled $N$ th floor building shown in Figure 2(a) is considered. The equation of motion is developed as

$$
\mathbf{M}_{b} \ddot{\mathbf{x}}_{b}+\mathbf{C}_{b} \dot{\mathbf{x}}_{b}+\mathbf{K}_{b} \mathbf{x}_{b}=-\mathbf{M}_{b} \boldsymbol{\Gamma}_{b} \ddot{x}_{g}
$$

where $\mathbf{M}_{b}, \mathbf{C}_{b}$, and $\mathbf{K}_{b}$ are the structural mass, damping, and stiffness of the uncontrolled building, respectively, $\mathbf{x}_{b}$ is the structural deformation vector, $\boldsymbol{\Gamma}_{b}$ is a vector with entries equal to unity for translational DOFs and zero for others, and $\ddot{x}_{g}$ is the horizontal ground acceleration. The structural deformation vector $\mathbf{x}_{b}$ defined in this study consists of displacements and rotational angles as

$$
\mathbf{x}_{b}=\left[\begin{array}{lllllll}
x_{1} & \theta_{1} & x_{2} & \theta_{2} & \ldots & x_{N} & \theta_{N}
\end{array}\right]^{T}
$$

where $x_{j}$ and $\theta_{j}$ are the displacement and rotational angle relative to the ground of the $j$ th floor, respectively. Thus the mass matrix $\mathbf{M}_{b}$ is defined as

$$
\mathbf{M}_{b}=\operatorname{diag}\left[\begin{array}{lllllll}
m_{1} & I_{1} & m_{2} & I_{2} & \ldots & m_{N} & I_{N}
\end{array}\right]
$$

where $m_{j}$ and $I_{j}$ are the mass and mass moment inertia of the $j$ th floor, respectively. And the influence vector $\boldsymbol{\Gamma}_{b}$ is given by

$$
\boldsymbol{\Gamma}_{b}=\left[\begin{array}{lllllll}
1 & 0 & 1 & 0 & \ldots & 1 & 0
\end{array}\right]^{T}
$$


(a)

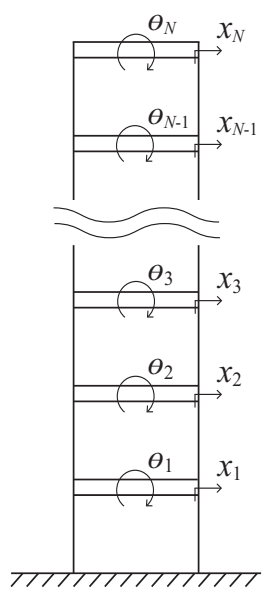

(b)

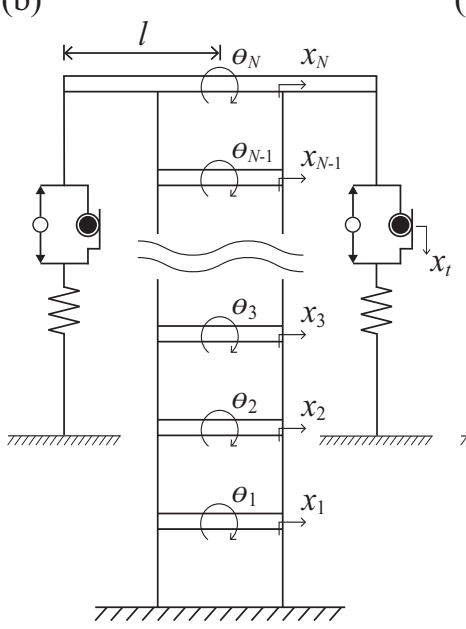

(c)

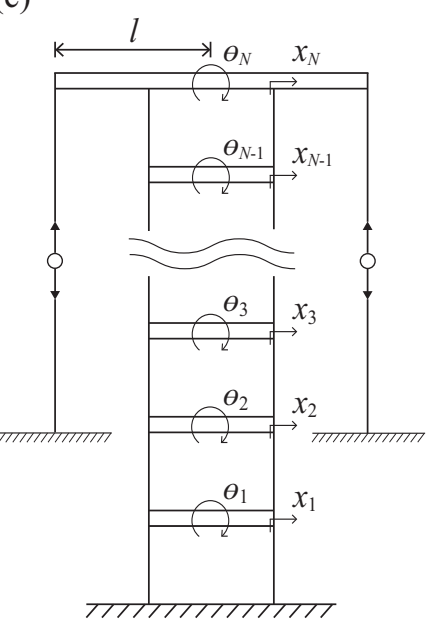

Figure 2: Building models (a) Uncontrolled building, (b) Building with TIMETs, (c) Building with ETs.

\subsection{Building with outrigger tuned inertial mass electromagnetic transducers}

Based on the uncontrolled building case, the equation of motion for the building model with the outrigger TIMETs as illustrated in Figure 2(b) is derived. Let $l$ be the distance from the center of the core to the tips of the TIMET. And considering the 1st mode shape of the building, we assume that the outrigger system is installed on the top floor in this research so that the efficiency of the outrigger TIMETs is maximized. Then the moment applied to the $N$ th floor from the TIMETs installed on the $N$ th floor becomes

$$
M_{t i, N}=l k_{t}\left(l \theta_{N}-x_{t}\right)
$$

where $k_{t}$ is the stiffness of the supporting spring and $x_{t}$ is the relative displacement of the inertial masses of the TIMETs. Let the structural deformation vector be defined as

$$
\mathbf{x}_{t i}=\left[\begin{array}{ll}
\mathbf{x}_{b}^{T} & x_{t}
\end{array}\right]^{T}
$$

then the equation of motion can be written as

$$
\mathbf{M}_{t i} \ddot{\mathbf{x}}_{t i}+\mathbf{C}_{t i} \dot{\mathbf{x}}_{t i}+\mathbf{K}_{t i} \mathbf{x}_{t i}=-\mathbf{M}_{t i} \boldsymbol{\Gamma}_{t i} \ddot{x}_{g}
$$

By taking Eq. (15) and the force equilibrium of the TIMET given by

$$
m_{t} \ddot{x}_{t}+c_{t} \dot{x}_{t}=k_{t}\left(l \theta_{N}-x_{t}\right)
$$

into account, $\mathbf{M}_{t i}, \mathbf{C}_{t i}$, and $\mathbf{K}_{t i}$ matrices can be developed as

$$
\mathbf{M}_{t i}=\left[\begin{array}{cc}
\mathbf{M}_{b} & \mathbf{0} \\
\mathbf{0} & m_{t}
\end{array}\right], \quad \mathbf{C}_{t i}=\left[\begin{array}{cc}
\mathbf{C}_{b} & \mathbf{0} \\
\mathbf{0} & c_{t}
\end{array}\right], \quad \mathbf{K}_{t i}=\left[\begin{array}{cc}
\mathbf{K}_{11} & \mathbf{K}_{12} \\
\mathbf{K}_{21} & k_{t}
\end{array}\right]
$$


where $m_{t}, k_{t}$, and $c_{t}$ are the summation of the equivalent mass, tuning spring stiffness, and damping coefficient of the TIMETs connected to the $N$ th floor, respectively, and

$$
\begin{gathered}
\mathbf{K}_{11}=\mathbf{K}_{b}+\operatorname{diag}\left[\begin{array}{lllll}
0 & 0 & \ldots & 0 & l^{2} k_{t}
\end{array}\right], \\
\mathbf{K}_{12}=\left[\begin{array}{lllll}
0 & 0 & \ldots & 0 & -l k_{t}
\end{array}\right]^{T}, \quad \mathbf{K}_{21}=\mathbf{K}_{12}^{T}
\end{gathered}
$$

Also, the equivalent mass of the TIMETs are not influenced by horizontal earthquake inputs, so $\boldsymbol{\Gamma}_{t i}$ is given by

$$
\boldsymbol{\Gamma}_{t i}=\left[\begin{array}{ll}
\boldsymbol{\Gamma}_{b}^{T} & 0
\end{array}\right]^{T}
$$

\subsection{Building with electromagnetic transducers}

Finally, to investigate the effect of the tuned inertial mass mechanism, the building model with electromagnetic transducers (ETs) instead of the TIMETs as shown in Figure 2(c) is investigated as well. Let the structural deformation vector be defined as

$$
\mathbf{x}_{e t}=\mathbf{x}_{b}
$$

Then the equation of motion is derived as

$$
\mathbf{M}_{e t} \ddot{\mathbf{x}}_{e t}+\mathbf{C}_{e t} \dot{\mathbf{x}}_{e t}+\mathbf{K}_{e t} \mathbf{x}_{e t}=-\mathbf{M}_{e t} \boldsymbol{\Gamma}_{e t} \ddot{x}_{g}
$$

where

$$
\mathbf{M}_{e t}=\mathbf{M}_{b}, \quad \mathbf{C}_{e t}=\mathbf{C}_{b}+\operatorname{diag}\left[\begin{array}{lllll}
0 & 0 & \ldots & 0 & l^{2} c_{t}
\end{array}\right], \quad \mathbf{K}_{e t}=\mathbf{K}_{b}
$$

and

$$
\boldsymbol{\Gamma}_{e t}=\boldsymbol{\Gamma}_{b}
$$

\section{Design for outrigger tuned inertial mass electromagnetic transduc- ers}

The tuning spring stiffness and damping coefficient by the motor are designed to tune to the 1st mode of the uncontrolled building based on the method introduced in [3] as

$$
\begin{aligned}
k_{t} & =\left(\beta \omega_{1}\right)^{2} m_{t} \\
c_{t} & =2 \zeta \beta \omega_{1} m_{t}
\end{aligned}
$$

where $\omega_{1}$ is the natural frequency of the 1st mode of the uncontrolled building and $\beta$ is the optimum frequency ratio and $\zeta$ is the optimum damping coefficient of the 1st mode, which are expressed as

$$
\beta=\frac{1-\sqrt{1-4 \mu}}{2 \mu}, \quad \zeta=\frac{\sqrt{3-(1-\sqrt{1-4 \mu})}}{4}
$$


The mass ratio $\mu$ is defined as

$$
\mu=\frac{\boldsymbol{\Phi}^{T} \mathbf{M}_{t} \boldsymbol{\Phi}}{\boldsymbol{\Phi}^{T} \mathbf{M}_{b} \boldsymbol{\Phi}}
$$

where $\boldsymbol{\Phi}$ is the 1st mode shape vector of the building and $\mathbf{M}_{t}$ is defined as

$$
\mathbf{M}_{t}=\operatorname{diag}\left[\begin{array}{lllll}
0 & 0 & \ldots & 0 & l^{2} m_{t}
\end{array}\right]
$$

This design method is based on the fixed-point theory [1] and aims to reduce the response displacement. The details of this can be found in [3].

\section{Numerical simulations}

\subsection{Building model}

The building used in this study is the St. Francis Shangri-La Place in Philippines $[22,23,24]$. This 60 -story building has a height of $210 \mathrm{~m}$ and has 12 perimeter columns which are $20 \mathrm{~m}$ from the building center line. The concrete core is assumed to be $12 \mathrm{~m} \times 12 \mathrm{~m}$ with $0.5 \mathrm{~m}$ thickness. The total mass of the building is 30,000 tons and the outrigger system installed consists of 16 viscous dampers, 8 of which control the response in each of the two orthogonal directions. In this study, we consider only one direction and the TIMETs and ETs are employed instead of viscous dampers.

To create the model for evaluation, a vertical cantilever beam model based on the Bernoulli-Euler beam theory is applied. A finite element model is developed so that every story has one translational and one rotational degree of freedoms. Therefore, the total number of degrees-of-freedom should be 120 (60 in translation and 60 in rotation). The first 10 natural frequencies are $0.18,1.15$, $3.14,6.00,9.61,13.84,18.56,23.66,29.06$, and $34.66 \mathrm{~Hz}$, respectively. Damping of $2 \%$ is assumed in each mode.

The parameters for the outrigger TIMETs used in this article are summarized in Table 1. First the mass ratio defined as Eq. (29) is set as $\mu=0.05$ (TIMET (I)) and $\mu=0.1$ (TIMET (II)), and the values of the summation of the installed inertance $m_{t}$ are derived. Then the summation of the stiffness $k_{t}$, and damping $c_{t}$ are calculated based on Eqs. (26) and (27), respectively. The value of $\bar{c}_{t}$ depends on the motor and the lead conversion of the ball screw mechanism, thus this value can be determined relatively flexibly. Therefore we assume that $\bar{c}_{t}=10 c_{t}$ for numerical studies. In this study, to show the effect of the tuned inertial mass mechanism, the same values are employed for $k_{t}$ and $c_{t}$ of the building with the outrigger ETs and numerical simulations are carried out in parallel.

Using the determined parameter values, the transfer functions from input earthquake acceleration to the relative displacement and absolute acceleration

of the 60th floor are developed. The magnitudes for the cases of the uncontrolled building and the one with TIMET (II) are depicted in Figure 3. As can be seen, the TIMET mechanism reduces the peak of the 1st mode significantly without 
Table 1: Parameters for the outrigger TIMETs

\begin{tabular}{c|c|c} 
& TIMET $(\mathrm{I})$ & TIMET $(\mathrm{II})$ \\
\hline$\mu$ & 0.05 & 0.1 \\
$m_{t}(\mathrm{ton})$ & 87505 & 175010 \\
$k_{t}(\mathrm{kN} / \mathrm{m})$ & 131693 & 300158 \\
$c_{t}(\mathrm{kN} \mathrm{s} / \mathrm{m})$ & 30207 & 94236
\end{tabular}

(a)
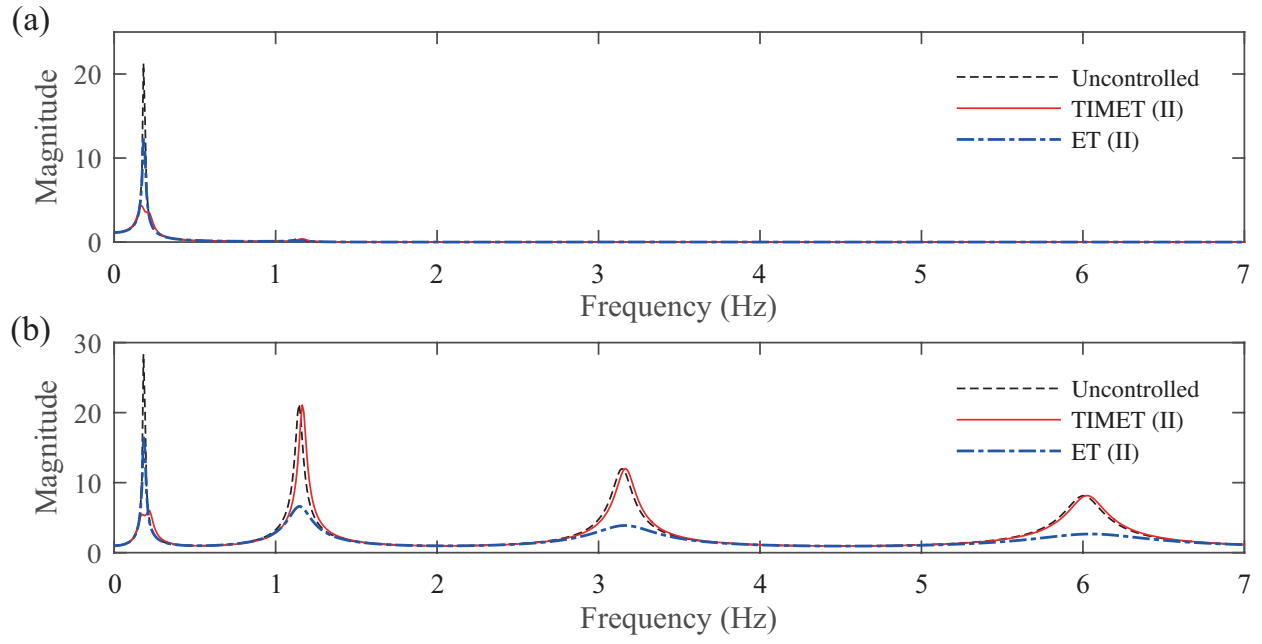

Figure 3: Transfer function from input acceleration to the 60th floor: (a) Displacement, (b) Acceleration.

affecting the higher modes as intended, while the ET case reduces the peaks of the all modes evenly. Also, the figures show that the response accelerations are easily influenced by the higher mode comparing to the response displacements.

\subsection{Time history analyses}

The long period earthquakes used for time history analyses are the EW component of the 2003 Tokachioki earthquake recorded in Tomakomai [25], the 2011 Tohoku earthquake in Osaka [25], and an artificial record assuming the Nankai Trough earthquake in Tokyo area, which is produced by the Building Research Institute, Japan [26]. The time histories of the ground accelerations of these earthquakes are shown in Figure 4.

The results obtained by the numerical simulation studies are shown for the three cases. The peak and root-mean-square (RMS) values of the relative displacements and absolute accelerations of the 20th, 40th, and 60th floors are summarized in Tables 2, 3, and 4. In these table, the peak and RMS values are denoted by $p$ and $\sigma$, respectively and the subscripts $\mathrm{d}$ or a and digit indicate 
(a)

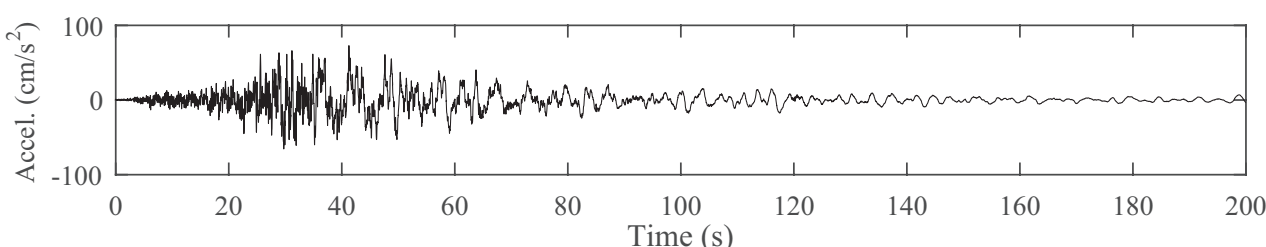

(b)

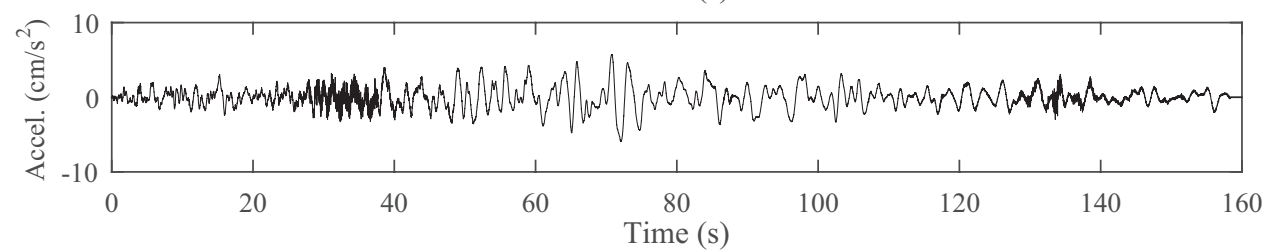

(c)

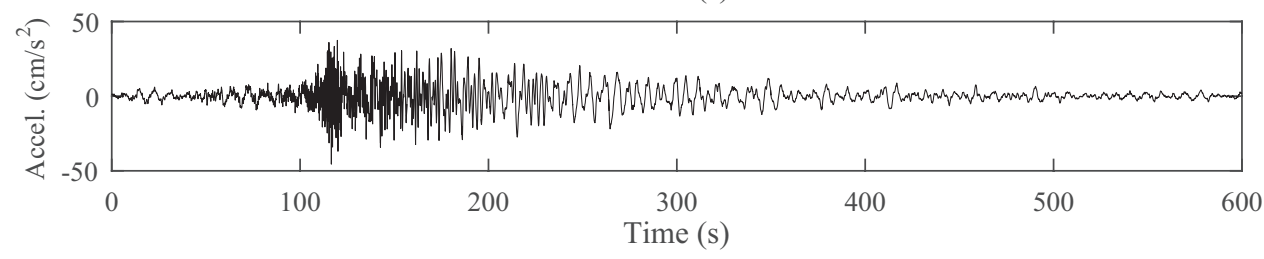

Figure 4: Input earthquakes: (a) Tokachioki, (b) Tohoku, (c) Nankai Trough.

displacement or acceleration and floor number. Also, the averaged generated power $\bar{P}_{g}$, the generated energy defined as

$$
E_{g}=\int_{0}^{t_{f}} P_{g}(t) d t
$$

and the input energy during the duration of time 0 to $t_{f}$ defined as [27]

$$
E_{i n}=-\int_{0}^{t_{f}} \sum_{j=1}^{60} m_{j} \ddot{x}_{g} \dot{x}_{s, j} d t
$$

are summarized in the tables as well as the energy conversion ratio defined as

$$
E_{r}=\frac{E_{g}}{E_{\text {in }}} \times 100
$$

Note that $t_{f}$ is $200 \mathrm{~s}$ for the Tokachioki, $160 \mathrm{~s}$ for the Tohoku, and $600 \mathrm{~s}$ for the Nankai Trough earthquake. From these tables, the building with the outrigger TIMET mechanism shows better performance in reducing response displacements and increasing energy absorbing capability to the three earthquake inputs. While the proposed structure does not work well to reduce response accelerations especially to the Nankai Trough earthquake. This is attributed to the fact that the parameters are designed based on the method to reduce the response displacements. Also, this is because the response accelerations are 
Table 2: Result for Tokachioki

\begin{tabular}{c|c|cc|cc} 
& Uncontrolled & TIMET (I) & ET (I) & TIMET (II) & ET (II) \\
\hline$p_{x, 20}(\mathrm{~cm})$ & 30.18 & 22.02 & 28.62 & 17.75 & 25.75 \\
$p_{x, 40}(\mathrm{~cm})$ & 98.32 & 70.03 & 93.19 & 55.96 & 83.56 \\
$p_{x, 60}(\mathrm{~cm})$ & 180.16 & 126.42 & 169.38 & 101.60 & 151.86 \\
$\sigma_{x, 20}(\mathrm{~cm})$ & 9.37 & 4.71 & 8.10 & 3.71 & 6.48 \\
$\sigma_{x, 40}(\mathrm{~cm})$ & 30.98 & 15.42 & 26.80 & 12.10 & 21.44 \\
$\sigma_{x, 60}(\mathrm{~cm})$ & 56.70 & 28.02 & 49.05 & 21.92 & 39.23 \\
\hline$p_{a, 20}\left(\mathrm{~cm} / \mathrm{s}^{2}\right)$ & 155.54 & 151.92 & 127.59 & 145.83 & 103.68 \\
$p_{a, 40}\left(\mathrm{~cm} / \mathrm{s}^{2}\right)$ & 172.72 & 140.78 & 150.73 & 130.14 & 139.89 \\
$p_{a, 60}\left(\mathrm{~cm} / \mathrm{s}^{2}\right)$ & 322.12 & 248.10 & 283.44 & 238.83 & 256.14 \\
$\sigma_{a, 20}\left(\mathrm{~cm} / \mathrm{s}^{2}\right)$ & 23.06 & 21.15 & 19.76 & 21.13 & 16.61 \\
$\sigma_{a, 40}\left(\mathrm{~cm} / \mathrm{s}^{2}\right)$ & 43.94 & 26.01 & 37.76 & 22.73 & 30.26 \\
$\sigma_{a, 60}\left(\mathrm{~cm} / \mathrm{s}^{2}\right)$ & 82.57 & 48.80 & 71.13 & 43.04 & 57.01 \\
\hline $\bar{P}_{g}(\mathrm{~kW})$ & - & 111.54 & 40.51 & 104.60 & 81.08 \\
$E_{g}(\mathrm{kWh})$ & - & 6.20 & 2.25 & 5.81 & 4.50 \\
$E_{i n}(\mathrm{kWh})$ & 8.80 & 9.16 & 9.09 & 7.93 & 9.23 \\
$E_{r}(\%)$ & - & 67.7 & 24.8 & 73.3 & 48.8
\end{tabular}

susceptible to the higher modes whose peaks the TIMET does not reduce as shown in Figure 3 as stated previously.

The time histories of the relative displacements of the 60th floor and the generated powers obtained from the parameters for $\mu=0.1$ are compared in Figures 5, 6, and 7. In these figures, the superiorities of the TIMET over the ET can be found in both mitigating response displacements and improving energy absorbing efficiency to the long period earthquakes. Thus these results show that the validity of the TIMET designed to reduces the peak of the magnitude of the 1st mode intensively as shown in Figure 3 for the high-rise building subject to the long period earthquakes.

\section{Conclusions}

The primary purpose of this paper is to introduced the outrigger tuned inertial mass electromagnetic transducer (TIMET) for the purpose of the seismic protection of high-rise buildings. The analytical model for the proposed system was developed and the magnitude of the transfer function showed that the peak of the 1st mode of the high-rise building was reduced significantly. Also the effectiveness of the proposed outrigger tuned inertial mass mechanism to long period earthquake excitations for vibration response reduction was observed in the time history response analyses. At the same time, it was demonstrated that the outrigger TIMET improves energy generation efficiency to a large extent with the input energy to the structure kept low. 
Table 3: Result for Tohoku

\begin{tabular}{c|c|cc|cc} 
& Uncontrolled & TIMET (I) & ET (I) & TIMET (II) & ET (II) \\
\hline$p_{x, 20}(\mathrm{~cm})$ & 2.25 & 1.22 & 2.06 & 1.05 & 1.75 \\
$p_{x, 40}(\mathrm{~cm})$ & 7.56 & 4.09 & 6.96 & 3.51 & 5.95 \\
$p_{x, 60}(\mathrm{~cm})$ & 13.99 & 7.51 & 12.88 & 6.37 & 11.02 \\
$\sigma_{x, 20}(\mathrm{~cm})$ & 0.75 & 0.44 & 0.67 & 0.35 & 0.55 \\
$\sigma_{x, 40}(\mathrm{~cm})$ & 2.49 & 1.44 & 2.21 & 1.13 & 1.84 \\
$\sigma_{x, 60}(\mathrm{~cm})$ & 4.56 & 2.60 & 4.05 & 2.03 & 3.36 \\
\hline$p_{a, 20}\left(\mathrm{~cm} / \mathrm{s}^{2}\right)$ & 9.94 & 8.89 & 9.09 & 8.48 & 8.00 \\
$p_{a, 40}\left(\mathrm{~cm} / \mathrm{s}^{2}\right)$ & 10.85 & 7.26 & 9.86 & 6.90 & 8.38 \\
$p_{a, 60}\left(\mathrm{~cm} / \mathrm{s}^{2}\right)$ & 24.28 & 15.25 & 21.89 & 13.28 & 18.31 \\
$\sigma_{a, 20}\left(\mathrm{~cm} / \mathrm{s}^{2}\right)$ & 2.06 & 1.92 & 1.77 & 1.85 & 1.53 \\
$\sigma_{a, 40}\left(\mathrm{~cm} / \mathrm{s}^{2}\right)$ & 3.51 & 2.34 & 3.07 & 1.97 & 2.53 \\
$\sigma_{a, 60}\left(\mathrm{~cm} / \mathrm{s}^{2}\right)$ & 6.82 & 4.68 & 6.00 & 4.02 & 5.01 \\
\hline$P_{g}(\mathrm{~kW})$ & - & 1.04 & 0.29 & 0.99 & 0.65 \\
$E_{g}(\mathrm{kWh})$ & - & 0.05 & 0.01 & 0.04 & 0.03 \\
$E_{i n}(\mathrm{kWh})$ & 0.05 & 0.07 & 0.05 & 0.06 & 0.06 \\
$E_{r}(\%)$ & - & 65.9 & 24.6 & 71.6 & 49.0
\end{tabular}

\section{Acknowledgement}

This research was supported by JSPS KAKENHI Grant number 17H04942. This support is gratefully acknowledged. The authors would like to thank the National Research Institute for Earth Science and Disaster Resilience and Building Research Institute for providing the earthquake data.

\section{References}

[1] J. P. Den Hartog, Mechanical Vibrations, Civil, Mechanical and Other Engineering Series, Dover Publications, New York, NY, 1985.

URL https://books.google.co.jp/books?id=-Pu5YlgY4QsC

[2] G. W. Housner, L. Bergman, T. Caughey, A. Chassiakos, R. Claus, S. Masri, R. Skelton, T. Soong, B. F. Spencer, Jr., J. Yao, Structural control: Past, present, and future, Journal of Engineering Mechanics 123 (9) (1997) 897-971.

[3] K. Ikago, K. Saito, N. Inoue, Seismic control of single-degree-of-freedom structure using tuned viscous mass damper, Earthquake Engineering \& Structural Dynamics 41 (3) (2012) 453-474. doi:10.1002/eqe.1138.

[4] I. F. Lazar, S. Neild, D. Wagg, Using an inerter-based device for structural vibration suppression, Earthquake Engineering \& Structural Dynamics 43 (8) (2014) 1129-1147. doi:10.1002/eqe. 2390. 
Table 4: Result for Nankai Trough

\begin{tabular}{c|c|cc|cc} 
& Uncontrolled & TIMET (I) & ET (I) & TIMET (II) & ET (II) \\
\hline$p_{x, 20}(\mathrm{~cm})$ & 22.57 & 12.46 & 19.63 & 9.30 & 15.72 \\
$p_{x, 40}(\mathrm{~cm})$ & 74.69 & 41.01 & 65.00 & 30.42 & 51.80 \\
$p_{x, 60}(\mathrm{~cm})$ & 136.67 & 74.72 & 118.99 & 55.26 & 94.54 \\
$\sigma_{x, 20}(\mathrm{~cm})$ & 5.70 & 2.83 & 4.85 & 2.36 & 3.83 \\
$\sigma_{x, 40}(\mathrm{~cm})$ & 18.84 & 9.28 & 16.03 & 7.68 & 12.64 \\
$\sigma_{x, 60}(\mathrm{~cm})$ & 34.46 & 16.96 & 29.31 & 13.99 & 23.10 \\
\hline$p_{a, 20}\left(\mathrm{~cm} / \mathrm{s}^{2}\right)$ & 117.09 & 112.86 & 89.21 & 117.04 & 68.02 \\
$p_{a, 40}\left(\mathrm{~cm} / \mathrm{s}^{2}\right)$ & 100.30 & 78.53 & 88.86 & 80.74 & 71.42 \\
$p_{a, 60}\left(\mathrm{~cm} / \mathrm{s}^{2}\right)$ & 190.76 & 186.57 & 165.94 & 184.49 & 134.09 \\
$\sigma_{a, 20}\left(\mathrm{~cm} / \mathrm{s}^{2}\right)$ & 14.28 & 13.75 & 12.16 & 15.08 & 9.94 \\
$\sigma_{a, 40}\left(\mathrm{~cm} / \mathrm{s}^{2}\right)$ & 26.80 & 15.69 & 22.74 & 14.80 & 17.96 \\
$\sigma_{a, 60}\left(\mathrm{~cm} / \mathrm{s}^{2}\right)$ & 50.35 & 30.16 & 42.43 & 29.61 & 32.98 \\
\hline $\bar{P}_{g}(\mathrm{~kW})$ & - & 32.55 & 14.09 & 33.71 & 26.56 \\
$E_{g}(\mathrm{kWh})$ & - & 5.43 & 2.35 & 5.62 & 4.43 \\
$E_{i n}(\mathrm{kWh})$ & 9.59 & 8.32 & 9.47 & 7.96 & 9.08 \\
$E_{r}(\%)$ & - & 65.2 & 24.8 & 70.6 & 48.7
\end{tabular}

[5] S. Krenk, J. Høgsberg, Tuned resonant mass or inerter-based absorbers: unified calibration with quasi-dynamic flexibility and inertia correction, Proceedings of the Royal Society of London A: Mathematical, Physical and Engineering Sciences 472 (2185). doi:10.1098/rspa.2015.0718.

[6] L. Marian, A. Giaralis, Optimal design of a novel tuned mass-damper-inerter (TMDI) passive vibration control configuration for stochastically support-excited structural systems, Probabilistic Engineering Mechanics 38 (2014) $156 \quad-164$. doi:https://doi.org/10.1016/j.probengmech.2014.03.007.

[7] S. Y. Zhang, J. Z. Jiang, S. Neild, Optimal configurations for a linear vibration suppression device in a multi-storey building, Structural Control and Health Monitoring 24 (3) (2017) n/a-n/a. doi:10.1002/stc.1887.

[8] M. C. Smith, Synthesis of mechanical networks: the inerter, IEEE Transactions on Automatic Control 47 (10) (2002) 1648-1662. doi:10.1109/TAC.2002.803532.

[9] F.-C. Wang, M.-F. Hong, T.-C. Lin, Designing and testing a hydraulic inerter, Proceedings of the Institution of Mechanical Engineers, Part C: Journal of Mechanical Engineering Science 225 (1) (2011) 66-72. doi:10.1243/09544062JMES2199.

[10] M. Saitoh, On the performance of gyro-mass devices for displacement miti- 
(a)
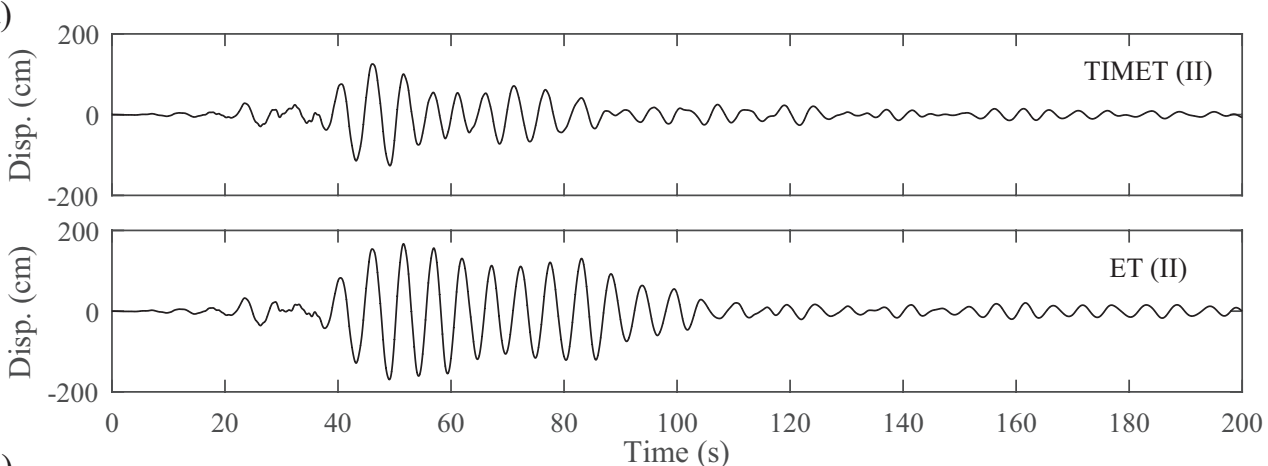

(b)
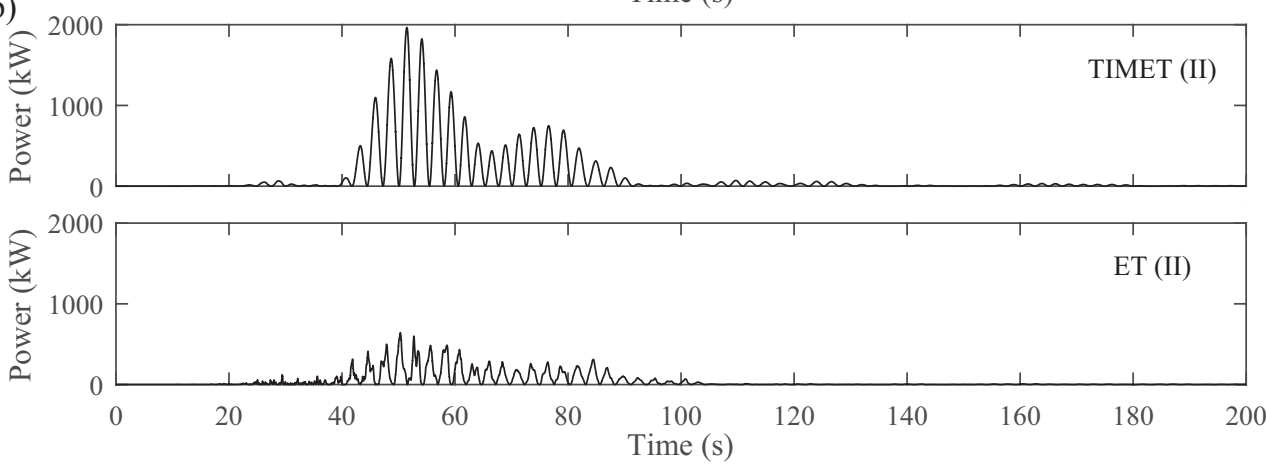

Figure 5: Time histories for Tokachioki: (a) Displacement of the 60th floor, (b) Generated power.

gation in base isolation systems, Structural Control and Health Monitoring 19 (2) (2012) 246-259. doi:10.1002/stc. 419.

[11] Y. Watanabe, K. Ikago, N. Inoue, H. Kida, S. Nakaminami, H. Tanaka, Y. Sugimura, K. Saito, Full-scale dynamic tests and analytical verification of a force-restricted tuned viscous mass damper, in: Proceedings of the 15th World Conference on Earthquake Engineering, Lisbon, Portugal, 2012.

[12] T. Asai, Y. Araki, K. Ikago, Energy harvesting potential of tuned inertial mass electromagnetic transducers, Mechanical Systems and Signal Processing 84, Part A (2017) 659 -672. doi:10.1016/j.ymssp.2016.07.048.

[13] T. Asai, Y. Araki, K. Ikago, Structural control with tuned inertial mass electromagnetic transducers, Structural Control and Health Monitoring n/a-n/adoi:10.1002/stc. 2059.

[14] L. Marian, A. Giaralis, The tuned mass-damper-inerter for harmonic vibrations suppression, attached mass reduction, and energy harvesting, Smart Structures \& Systems 19 (6) (2017) 665 - 678. doi:10.12989/sss.2017.19.6.665. 
(a)
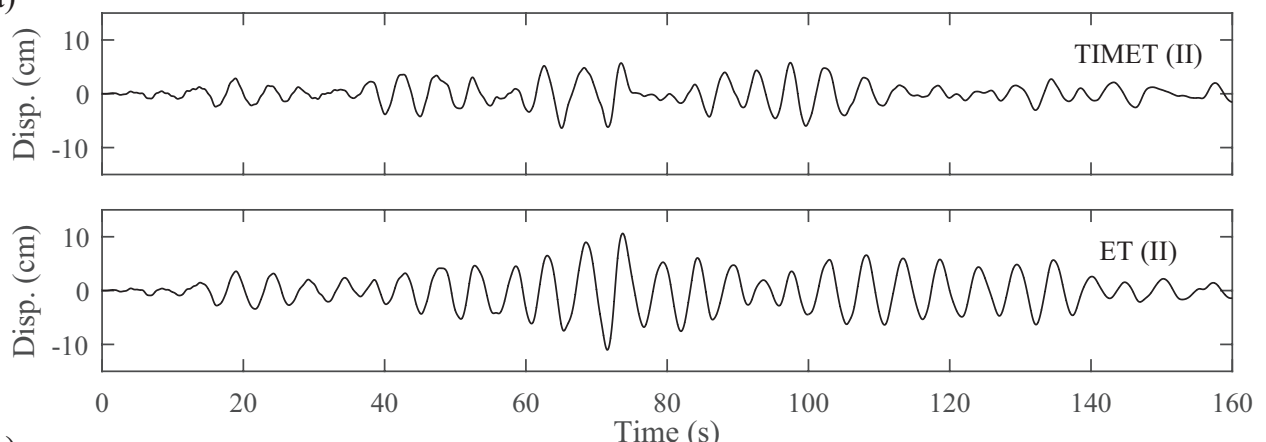

(b)

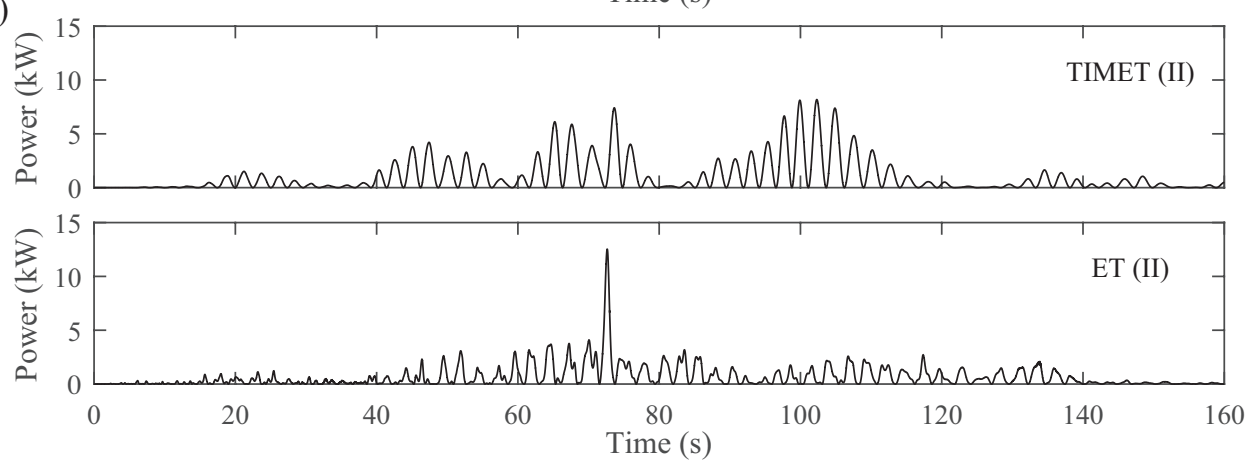

Figure 6: Time histories for Tohoku: (a) Displacement of the 60th floor, (b) Generated power.

[15] Y. Nakamura, T. Hanzawa, Performance-based placement design of tuned electromagnetic inertial mass dampers, Frontiers in Built Environment 3 (2017) 26. doi:10.3389/fbuil.2017.00026.

[16] B. S. Smith, I. Salim, Parameter study of outrigger-braced tall building structures, Journal of the Structural Division 107 (10) (1981) 2001-2014.

[17] J. Charles, Application of damping in high-rise buildings, Master's thesis, M.I.T. (2006).

[18] R. J. Smith, M. R. Willford, The damped outrigger concept for tall buildings, The Structural Design of Tall and Special Buildings 16 (4) (2007) 501-517. doi:10.1002/tal.413.

[19] T. Asai, J. T. Scruggs, Nonlinear stochastic control of self-powered variabledamping vibration control systems, in: 2016 American Control Conference (ACC), Boston, MA, 2016, pp. 442-448. doi : 10.1109/ACC. 2016.7524954.

[20] I. L. Cassidy, J. T. Scruggs, Nonlinear stochastic controllers for power-flowconstrained vibratory energy harvesters, Journal of Sound and Vibration 332 (13) (2013) $3134-3147$. 
(a)
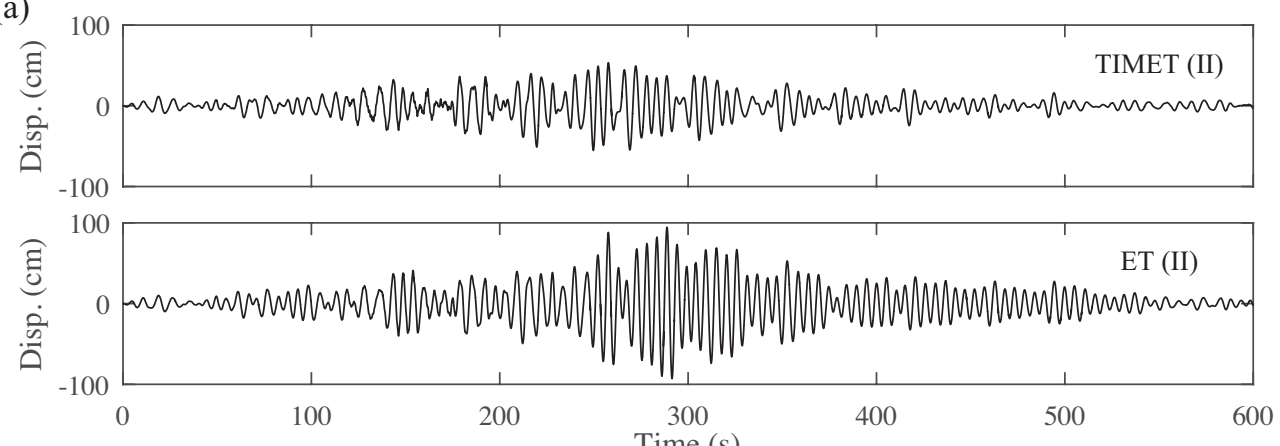

(b)

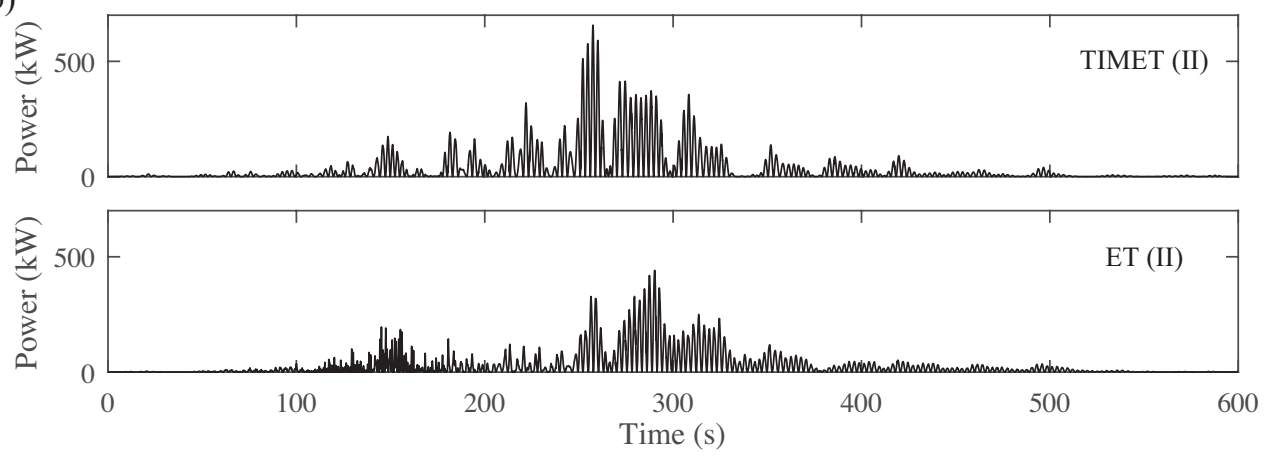

Figure 7: Time histories for Nankai Trough: (a) Displacement of the 60th floor, (b) Generated power.

[21] I. L. Cassidy, J. T. Scruggs, Statistically linearized optimal control of an electromagnetic vibratory energy harvester, Smart Materials and Structures 21 (8) (2012) 085003.

[22] C.-M. Chang, Z. Wang, B. F. J. Spencer, Z. Chen, Semi-active damped outriggers for seismic protection of high-rise buildings, Smart Structures and Systems 11 (5) (2013) 435-451. doi:10.12989/sss.2013.11.5.435.

[23] T. Asai, K. Ikago, Y. Araki, Outrigger tuned viscous mass damping system for high-rise buildings subject to earthquake loadings, in: 6AESE/11ANCRiSST Joint Conference, Urbana, IL, 2015.

[24] T. Asai, C.-M. Chang, B. M. Phillips, B. Spencer, Real-time hybrid simulation of a smart outrigger damping system for highrise buildings, Engineering Structures $57 \quad(2013) \quad 177 \quad-\quad 188$. doi:10.1016/j.engstruct.2013.09.016.

[25] National Research Institute for Earth Science and Disaster Resilience, http://www.kyoshin.bosai.go.jp/, accessed: 2017-08-10. 
[26] Building Research Institute, http://www.kenken.go.jp/english/index.html, accessed: 2017-08-10.

[27] A. Chopra, Dynamics of Structures: Theory and Applications to Earthquake Engineering, Prentice Hall International Series in Civil Engineering And, Pearson/Prentice Hall, Upper Saddle River, NJ, 2007. 